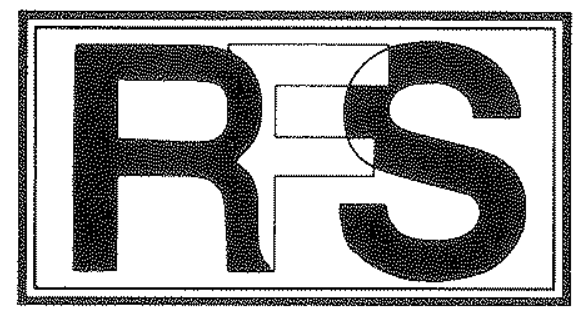

Revista de Fomento Social, $48(1993), 499-512$

\title{
Universidad y sociedad en España: ¿el final de un ciclo?
}

El autor reflexiona sobre el papel que ha jugado la universidad en la sociedad civil y religiosa de España a lo largo de la historia. Trata en primer lugar la creación de la universidad con el doble objetivo de la creación del saber y de la formación de dirigentes. En las que denomina universidad de la burguesia y universidad moderna observa que además de estos objetivos, se organizaron para formar profesionales, al tiempo que se abrieron a las nuevas lineas del pensamiento cientifico. En relación con la actual universidad subraya la masificación, la proliferación de universidades y el descenso de la calidad docente. Como soluciones a esta situación propone la desmitificación de los estudios universitarios, la integración de la formación profesional en la universidad y la mejora de la calidad docente.

José Ignacio CUBERO SALMERON

(*)

(*) Profesor de la Escuela Técnica Superior de Ingenieros Agrónomos de Córdoba. 
Al escribir sobre un tema como el que figura en el título, tan debatido, tan soberanamente bien debatido por plumas maravillosas (¿seránecesario recordar la Misión de la Universidad de Ortega?), tan del dominio de la prensa y de la calle, el autor debe ser cuidadoso, por el respeto que el lector merece, y tratar de evitar repeticiones de análisis previos, (y si se subraya aquí la palabra tratar es porque verosímilmente es labor imposible). Sólo cabe para ello, pues, reflexionar sobre el tema desde un punto de vista personal, el de un universitario de finales del siglo $X X$ que lleva toda su vida en la docencia y en la investigación. Una reflexión sobre lo que la Universidad fue, sobre lo que está siendo en este nuestro tiempo y sobre lo que puede preverse que va a ser, que quizá sólo sea el deseo sobre lo que, para el autor, debería llegar a ser. Todo ello, evidentemente, sobre la Universidad española.

\section{Las razones del pasado}

No es posible ignorar la Historia. Poco se aprende de ella en otros campos, o mejor dicho, poca eficacia práctica tienen sus enseñanzas para los gobemantes, pero en todo caso siempre permite trazar el camino recorrido, elemento indispensable en cualquier prediccion, como sabe cualquier estudiante de estadística elemental. Se me perdonará el excluir la llamada "Universidad de Córdoba" de la época califal, pues los estudios que se realizaban en la capital del Califato se estructuraban de foma análoga a las actuales universidades islámicas. Ni sus funciones ni su organización son equivalentes a las de las
universidades occidentales.

Las universidades de las que descienden las actuales comenzaron siendo congregaciones de profesores y alumnos formadas no sólo para la transmisión de conocimientos sino para facilitar, y aún forzar, la creación de nuevo saber. La labor se sistematizó y el conjunto de profesores, alumnos, saberes y quehaceres se protegi 6 de manera institucional por las autoridades eclesiásticas (las primeras en hacerlo: en la Edad Media, poca actividad intelectual habia fuera de la Iglesia) y civiles. Es evidente que la protección oficial, más perfecta que un simple mecenazgo por generoso que fuera, permitio la continuidad del nuevo organismo, permitiendo que docentes y discentes utilizaran su tiempo exclusivamente en aquello para lo que se habian asociado. El ora et labora de los monasterios se transformo en un doce, disce, sin que hiciera falta un labora

\section{RFS}


en forma de irabajo manual para mantenerse.

No cabe pensar que esa Universidad naciente se hubiera creado exclusivamente para el placer del saber por el saber, aun cuando se reconociera la importancia de su mantenimiento y transmisión. Las autoridades civiles y religiosas eran conscientes de la necesidad de buenos cuadros dirigentes, de lo que hoy llamarímos funcionarios bien preparados. La Universidad surtió a unas y a otras con generosidad. No es de extrañar, pues, que los programas curriculares incluyeran lo que entonces había que saber. La preparación filosófica y teológica era la cúspide de todo el sistema, y teniendo en cuenta lo monolítico de las ideas medievales en cuanto a religión, puede comprenderse que las ideas enseñadas eran las de la mas pura ortodoxia. No se entienda filosofia como lo que después se impartió en nuestras Facultades: desde los primeros filosofos, la Filosofía lo abarcaba prácticamente todo; no hay más que recordar la importancia extraordinaria que Platon y Aristóteles le dieron a las matemáticas, y el segundo, además, a lo que hoy llamamos ciencias naturales. No es posible aquí extenderse en la sistematización de las enseñanzas en los tantas veces mencionados trivium (que en su forma más conocida abarcaba gramática, retorica y dialéctica) y quadrivium (que, por su parte, comprendía aritmética, geometría, música y astronomía), ni en su subordinacion a la filosofia, y la de ésta a la teología, ni en su creciente especialización que condujo, en épocas ya modemas, a nuestra clásica división en letras y ciencias, aunque la equivalencia sea más por analogía que por homología: la identidad en nombres de lo que hoy son disciplinas o simples asignaturas con to que entonces fueron sólo puede llevar a la confusión.

El resultado de las universidades salta a la vista: su creación se extendió como reguero de polvora y, como la misma polvora, produjo enormes llamaradas de todo estilo, incluso físicas en algún que otro auto de fe. Su eficacia en la preparación de élites era evidente, como también resultaron serlo las dificultades que esas asociaciones de profesores y alumnos iban produciendo en los dogmas laicos y religiosos que había que transmitir. No se reúne a las mejores cabezas para que se limiten a aceptar lo que alguien afirmo en el pasado. De la exposición surge el comentario y de éste la crítica, y de la crítica una nueva manera de verlas cosas, ontodoxa o no. Los patrocinadores trataron de mantener el orden apelando a todas las fuerzas posibles, mentales y físicas. Pero la Universidad era fuego. Como la ortodoxia no podía cambiarse, las universida- 
des, con mayoro menor fortuna, se independizaron de sus patronos cuando éstos no admitieron la libertad de pensamiento junto con su protección. Todos los casos posibles ocurrieron en el pasado.

En nuestro país prevaleció la ortodoxia dura. A principios del XIX, José María Blanco estudiaba en la Universidad de Sevilla la imposibilidad del vacío, el horror de la Naturaleza; y él mismo escribió mucho más tarde en sus Cartas de España el choque mental que le produjo saber que ya había una máquina que hacía el vacío... Lo que le sucedió a quien llamamos ahora Blanco-White debio ocurrir con frecuencia; Blanco se rebeló y se expatrió; muchos otros debieron seguir ese camino, otros muchos pudieron terminar en cárceles o más allá, muchos más se callaron y aceptaron o fingieron aceptar lo que se les enseñaba. Un país que había producido figuras como Suárez, Vitoria, de las Casas, Vives, Servet y tantos y tantos otros, vio eliminado el espíritu crítico, que es consubstancial con el pensamiento, a cambio de un mantenimiento feroz de una feroz ortodoxia, sin siquiera plantearse que la capacidad de crítica no tiene porqué necesariamente producir heterodoxia (dejando de lado el preguntamos
qué es heterodoxia).

¿Quién accedía a la Universidad? No ciertamente lo que hoy entendemos por pueblo: "Universitas" se refería a lo que se enseñaba, no a quién se enseñaba. En las creadas por órdenes religiosas, sus propios elegidos; en las que hoy llamariamos "públicas", si acaso algún paje acompañando a su señor. Aún más difícil era el ingreso, por cuanto en nuestro país se aplicó el criterio de la limpieza de sangre para ser admitido en los Colegios Mayores y Menores en que Se organizaban las universidades, y que estuvo en vigor hasta la desaparición de la universidad clásica tras las guerras napoleonicas. No siempre se aplicaba con rigor (léase de nuevo las Cartas de España), pero esa posibilidad existía, lo que limitó aún más el número de potenciales universitarios.

\section{La Universidad de la burguesía}

Como acaba de decirse, toda esta organización se borró tras las guerras napoleónicas. No fueron sólo ellas, ciertamente; en toda Europa corrían tiempos de reforma en todos los aspectos del vivir. El siglo XVIII había estado marcado por los triunfos de la burguesía y de las revoluciones industrial y agrícola, es decir, de la técnica. La Universidad se transformó profundamente en Europa (únicamen-

\section{RFS}


te Inglaterra se mantuvo como un islote aparte, y aún se puede reconocer la organización clásica en sus universidades de más solera) y a la española le llegó su tumo. Y ya era hora. Si se recuerda la opinión que a Diego de Torres Villarroel, catedrático de matemáticas de Salamanca -por otro lado excelente escritor- le merecían las teorias de Newton no hara falta ulterior comentario.

Fue una lástima que los déspotas ilustrados no tuvieran tiempo para la reforma desde dentro, para romper el aislamiento intelectual a que se había llegado. Es el caso que a los Borbones ilustrados les sucedieron otros "deslustrados" y que, cuando en España se entronizó finalmente un régimen constitucional, ya no se pudo volver al pasado. La Universidad se reformó definitivamente con el modelo europeo a la vista y se reorganiz 6 en la forma en que hallegado a nuestros días. Las universidades se extendieron geograficamente, dejando de lado algunas que, por motivos increíbles, el gobierno de Fernando VII había eliminado, se abrieron a la clase media (recuérdese que esta universidad estaba creada tras el triunfo de la burguesía) y, sobre todo, se abrieron a las ideas, no sin dificultades: no fueron pocos los profesores universitarios expedientados, expatriados, repelidos, y no sabemos el número de los candidatos que sencillamente no llegaron a causa de esa nueva libertad de enseñanza en las aulas universitarias. Esa lucha entre universitarios y poder, "poder" que simplemente puede ser una situación establecida por el mundo circundante, aún la hemos conocido en tiempos recientes.

La Nueva Universidad Española se convirtió así en palenque y palestra, y no hubo ya acontecimiento social, político o científico dentro y fuera del país que no tuviera su repercusión en ella. Se repetía así la historia: del mismo modo que las primeras universidades habían sido foro para las críticas a doctrinas teológicas o filosoficas, esto es, para el pensamiento que caracterizaba a la clase social que las había creado, resultando ser así su conciencia, esta Nueva Universidad cumplía el mismo papel para las clases que la habían recreado: la alta y la media. Por la propia indefinición de esta última, era claro que resonaban también los problemas del obrero, problemas que repercutían en todo el andamiaje de la sociedad del XIX y luego del XX. Esta Nueva Universidad no estaba ya sobre la sociedad, preparando dirigentes engendrados por los ya dirigentes, como lo estaba su antecesora, la Universidad "clásica": puede decirse que al haber incorporado a la burguesía, la Universidad se hizo parte, por primera vez, del tejido social. 


\section{El papel de Ua Universidad moderna}

La actividad de la universidad que ha llegado hasta nuestro tiempo no fue ya preparar únicamente los cuadros de élite, sino a la clase media (en un principio, componentes. Ios niveles, perogura formando, y lo seguirá haciendo, funcionarios de todos técnicos y especian sua ámbito de acción, también salieron de sus aulas en principio, a to to tipo y nivel, curiosamente destinados, superiores en Er funcionarios. Recuérdese, por ejemplo, que las ingenierías dependían de los Ministeriosaban en las llamadas Escuelas Especiales que con la reforma de 1957, en respectivos. Esta situación acabo en nuestro país nombre actual de te, y también recienulas Técnicas Superiores. Olatransformación equivalenobligado un comentario: las Escuelas de Veterinaria en Facultades. Parece cieran formalmente a la Universubiera Centros de enseñanza que no pertenedad, no creo que ningún ingeniero o veterinario , no se considerara universitario. Lo mismo hanzas. La Nueva Universidad, a diferencia de la

\section{La Universidad contemporánea: fin de un ciclo evolutivo}

La nueva universidad iba así confundiéndose, esto es, fundiéndose, con la sociedad. La palabra "Universitas" ampliaba su significado. Su éxito, como el de su predecesora, fue indudable. Justamente es ese éxito el que motivó la última de sus aperturas, la que da origen a la universidad que estamos viendo nacer y que será la del siglo próximo. Los que aún no habían tenido acceso a la Universidad no podían dejar de observar la facilifad de colocación de los egresados, y el logico deseo de poder vivir mejor era suficiente acicate para que cualquier familia de escasos recursos los dedicara a tener al menos (no había para más) un hijo con título universitario. Muchas buenas cabezas lo lograron, frecuentemente con un coste humano extraordinario. La presión social que clamaba por una apertura, por una "igualdad de oportunidades" (jcomo si bastara para ello el ser universitario!) se hizo tremenda. Y la demagogia de los demagogos, los "jtú también tienes derecho!" sin contar con los medios, 
también se hizo insostenible.

Porotro lado, el espejo en que solo se reflejaba el éxito era un espejo de feria, pues ¿se tenía éxito por ser universitario o se iba a la universidad porque ya se estaba en la "rampa de lanzamiento" del éxito?. En la universidad clásica, ¿se terminaba siendo dirigente por estudiar en Salamanca o Alcalá, o se iba a Salamanca y Alcalá porque ya se tenían opciones a ser dirigente?. Quizá lo segundo. O mejor: lo segundo, ayudado por lo primero. Ahí no jugaron nunca, hasta ahora al menos, las "igualdades de oportunidades"...

Sea como fuere, puede decirse que si la Universidad del último tercio del siglo no ha incorporado ya a todos los segmentos que aún no tenían acceso a los estudios universitarios está en vías de hacerlo. La extraordinaria proliferación de Centros, Facultades y Universidades no parece sino el final de una larga historia evolutiva: se empez6 atrayendo a los muy selectos a unos pocos lugares específicos e inamovibles. Se termina llevando las universidades a todos los lugares.

Pero cabe preguntarse: ¿cuál es ahora la función de esta Universidad?. Hay que evitar un paralelismo ilícito: si al principio producía dirigentes de vástagos de dirigentes, si luego de hijos de profesionales modelaba profesionales, ¿formará, en el futuro, titulados en paro nacidos de titulados en paro?. Es un paralelismo ilícito porque, entre otras cosas, la situación de paro que se vive en tantos países, incluso en el mundo desarrollado, debe considerarse como algo coyuntural; y, además, porque la Universidad no ha sido nunca diletante (aunque hayan pasado diletantes por ella) y sí bien eficaz, tanto en la creación de nuevo conocimiento como en la formación para aplicar el existente, si un buen número de egresados "van al paro" es porque algo funciona mal en la sociedad, o porque ésta no ha sabido crear la Universidad a su medida, como supieron hacerlo las sociedades anteriores a ella.

\section{La creación desde dentro: evolución frente a creación}

Conviene en este momento hacer un inciso. La vision que he dado del origen de las universidades, esto es, de las Universidades características de dos épocas muy dilatadas, y admito por supuesto que caben otras interpretaciones, es como si cada tipo de sociedad hubiera diseñado $s u$ Universidad, para sus propios fines, escapándosele de las manos, eso sí, en lo que respecta a esa reacción en cadena 
que produce el cultivo en masa del espíritu crítico. Pero, en todo caso, como si la creación de la Universidad hubicra tenido lugar fuera de la sociedad correspondiente y a ella sobrepuesta. Pero ha habido casos que no se ajustan a ese patrón. Me limitaré a uno de ellos, no sólo porque es un buen modelo sino por la importancia que tiene en este tiempo nuestro: es el caso de algunas universidades americanas. Algunas tan sólo, puesto que la génesis de otras muchas es la misma que las de las europeas, como es lógico, puesto que las creo una sociedad europea.

Pero en la colonización de to que hoy conocemos como Estados Unidos de Norteamérica se formo muy rápidamente una nueva sociedad, de aluvión si se quiere, de inmigrados de mil culturas diferentes, la inmensa mayoría de los cuales sin la menor preparación en nada, con una tierra virgen por delante ("virgen" aunque no "desierta"; pero ese es otro tema) que había que cultivar si se queria vivir. Lo que allí se necesitaba era no ya formar autoridades sino formar agricultores, agricultores "de base", y de bien baja base. Los primeros "agricultural colleges" (esto es, "escuelas de agricultura") tenían esa humilde pero eficaz mision, y se creaban a medida de la demanda. Hasta 1857 eso es 10 que hicieron. En ese año se fundó el Michigan Agricultural College, al que poco después la "Morrill Act" dio ayuda federal: se había dado un salto cualitativo. No es este el lugar para extenderse en la interesante historia de esas "escuelas de agricultura" (en 1920 se registraban unas 70 ) y de sus hermanas las estaciones experimentales agrícolas, sino sólo mencionar que muchos de ellos fueron el embrión de prestigiosas universidades actuales (Michigan, Illinois, Cornell etc. etc.), en las que se convirtieron a base de añadir materias (economía, química agrícola etc.) a la pura enseñanza de la agronomía inicial, de incluir a la investigación como actividad esencial y de aprovechar ese núcleo, ya una Facultad en el sentido clásico de la palabra, como célula a la que añadirle otras ya bajo un prisma de universidad tradicional. Puede decirse que ese tipo de universidades se formaron desde dentro, no por decreto de un ente social superior.

El interés que tiene la creación de esas universidades es que su origen se basa en algo tan simple como es darle una formación profesional a quien lo necesita. Las universidades americanas han mantenido, sea cual sea su origen, ese espíritu, y en ellas se puede cursar cualquier materia, incluso aunque no tengan validez para la consecución de "créditos", esos créditos intelectuales a los que 
tanto tiempo dedicamos en España hoy en đía. La eficacia de esas instituciones primeras se deriva del hecho de haber nacido a causa de una necesidad, de la misma foma que nuestras universidades también fueron eficaces al responder a aquello para lo que se las creo.

También en Europa surgieron escuelas parecidas. En España, concretamente, tienen su paralelo en las antiguas escuelas de peritaje (nombre cuya devaluación no comprendo) y en estaciones experimentales, creadas muchas veces por iniciativa privada, algunas de las cuales tuvieron un papel de auténtico mérito en la puesta al día de no pocos conocimientos tan esenciales como prácticos. Pero la prueba de que el espíritu que las formó es diferente del que hizo lo propio con las equivalentes americanas es que buen número de éstas se convirtieron en universidades, bastantes de las cuales de gran prestigio, en tanto que de las nuestras no sólo no lo consiguio ninguna sino que la mayoría de ellas ni siquiera se ha integrado plenamente en al guna Universidad. $Y$ si se hace ahora aplicando la legislación vigente hasta sus últimas consecuencias, se integrarán desde arriba y provocando las fricciones lógicas de un encaje, a diferencia de la suavidad de adaptación de un proceso evolutivo.

$Y \sin$ embargo, son dos sociedades que sintie ron la misma necesidad. Era 16gico: en los incipientes Estados Unidos, había que enseñar a ser agricultores a multitud de ignorantes europeos de aluvión; en España, había que reciclar a multitud de ignorantes agricuttores anclados en la Edad Media. La diferencia estriba en que "las bases" de allí clamaban por ello en tanto que las de aquí creían no necesitarlo. Allí, organo y función se crearon al mismo tiempo y evolucionaron en armonía. Aquí, sencillamente, se implantó una prótesis...

Fruto de ese origen polifilético de la Universidad norteamericana es la existencia de distintos tipos de universidades, desde las de máximo prestigio fuertemente especializadas en estudios de tercer ciclo hasta aquellas de tipo regional, en muchas de las cuales se cursan preferentemente estudios de primer ciclo y en las cuales, en general, no se puede optar al doctorado en numerosas materias, incluso en ninguna. Si la calidad de enseñanza aumenta, el nivel de la universidad también lo hace. Un sistema universitario flexible.

El ejemplo americano enseña que cualquier foco de cultura, por insignificante que ésta sea en principio, actúa de fermento o de núcleo de condensación de mayores niveles culturales si se prestigia por su eficacia. 


\section{Espana, hoy}

Volvamos a la situación española actual. Masificación en aulas y laboratorios, proliferación de Universidades, de Facultades, de variadas Escuelas de no menos variados ciclos, de "campus" ( 6 o se dice "campi"?), de "másters" diversos en duración y doctrina, de programas de doctorado, de las llamadas "universidades de verano", de ascensos, por decreto, de centros de primer ciclo a centros de segundo ( $y$, porende, de tercero, puesto que entre ambos sólo media una formalidad), de "nuevas titulaciones"... Quien esto escribe no tiene conocimiento de nada parecido en otros lugares, al menos en la órbita occidental, y sí en cambio del caso relativamente reciente del Reino Unido, en el que el número de todos esos entes acabados de citar se redujo.

¿En qué se diferencia nuestra sociedad de las otras, nuestras acompañantes en el mundo desarrollado? De un lado, nuestra capacidad de análisis y de crítica es muy baja, quizá porque se le anuló a nuestra Universidad "clásica", y dado que las universidades etc., salvo muy pocas excepciones, siempre se crearon, en nuestro país, por decreto, recibimos la lluvia de creaciones como una muestra más de la actividad de nuestros gobernantes. Repercute en nuestros impuestos, claro está, pero sigue pareciendo polvora del Rey... Además, allí donde comienza un nuevo "ente docente" (universidad, titulación etc. etc.), lo único que se dice es que "se resuelve un tradicional problema" (o sea, "los hijos no tienen que ir a estudiar a otro sitio"), o que "se acaba con una situación discriminatoria" (esto es, "la provincia de al lado tenía y nosotros no"), y cosas por el estilo. Pero ¿es que no cabe algún otro tipo de análisis? ¿Se pregunta alguien si tal creación es necesaria? ¿Si realmente responde a algo más que a la facilidad geografica de obtener un título? ¿Va a servir para algo ese título salvo para quien parta ya de una situación de privilegio?.

De otro lado, y lo que sigue solapa con el razonamiento anterior, nuestra sociedad estaba hambrienta de títulos universitarios. En otros países, el acceso a la máxima institución de la cultura se había facilitado tiempo atrás, pero en España eso ha ocurrido de forma clara en tiempos recientes, y el hambre debía sermucha porque la respuesta fue superior, por lo aguda, a la habida en cualquier otro país. Quizá fue el aura de la Universidad como formadora de intelectuales, de dirigentes y de profesionales (entiéndase "de colocaciones"), sin analizar, 0 $\sin$ querer ver, que la mayoría de aquellos egresados ya estaban "colocados" a 
priori. Sea lo que fuere, la obsesión por un título universitario ha caladoen todos los estamentos, clases y castas del país. Y no estaría nada de mal saciar un hambre secular, en absoluto, si ese hambre fuera de cultura, si se persiguiera una formación superior. Pero, jay!, de eso no hablan ni los gobemantes ni los gobemados: aquellos porque rara vez tienen en cuenta las posibilidades con las que se cuenta (esto es, profesores adecuados, instalaciones convenientes); éstos porque no lo exigen, en particular los alumnos, cuya prisa en terminar es tan grande como escasa su crítica de qué reciben y cómo lo reciben. Se tiene hambre de títulos, pero de puro papel. No son pocos los casos en que se han completado ciclos enteros sin docencia por parte de especialistas. Y quizá alguien me diga que darle un nombre a una flor se aprende con tiempo y paciencia (vaya por delante que no estoy de acuerdo con ello), pero juna casa, un puente..., la agricultura que nos da de comer, la economía que nos salva o nos hunde... la salud...?

Finalmente, y a diferencia de oiras muchas sociedades, la nuestra no ha integrado la formación profesional entre las enseñanzas "de élite". Descende. mos, en el fondo, de antepasados cuya vanagloria era el no trabajar, como clara señal de que no se necesitaba para vivir. ¿Agricultores?: los moriscos. ¿Administradores, comerciantes?: los judíos. Si un cristiano acudía a la Universidad era, por tanto, para aprender algo que no implicara trabajo manual. ${ }_{¿} \mathrm{El}$ aprendizaje de los oficios?: a los gremios. Y si desaparecen los gremios, pues cada cual que se organice como pueda. $Y$ así, la enseñanza de oficios, por complejos o refinados que estos sean, y pueden darse un sinfín de ejemplos, no ha tenido nunca cabida en nuestro sistema universitario. Los intentos serios de elevar en calidad la llamada "Formacion Profesional", pues los ha habido, han sido siempre como formación fuera de la universidad. Así pues, si se tienen en cuenta simultáneamente el prestigio de ésta, el ansia de sus títulos por parte de los que tuvieron un difícil acceso a ella, la escasa consideración del aprendizaje de oficios y su exclusión de la enseñanza "superior", se comprenderá to acontecido en España: obsesión por el título universitario y simultáneamente rechazo de los oficios como materia digna de enseñanza. Compárese con el sistema americano, por ejemplo, y extráiganse conclusiones. 


\section{¿Soluciones? ¿Se cierra un ciclo milenario?}

¿Quién pone el cascabel...? Por coherencia conmigo mismo, he de proponer algunas ideas. El lector puede analizar la viabilidad de las mismas.

Habría que desmitificar los estudios universitarios desde el momento en que todo el mundo tiene ya acceso a la Universidad. Ya no se trata de que una casta superior gobernante o una clase media de profesionales mantengan las puertas cerradas. Las puertas están abiertas, y en España lo están en casi todas las capitales de provincia y en no pocos pueblos. Los ansiados títulos están, nunca mejor dicho, al cabo de la calle. En realidad, se intuye que la situacion es parecida a la habida en la segunda mitad del siglo pasado en relacion con el bachillerato. Pocos españoles eran entonces bachilleres, y los Institutos de Enseñanza Media aumentaron en número y se dispersaron por las tierras de España; no querría discutir aquí el hecho de que también iban dirigidos a una clase media y no a todos los estamentos sociales, pero tampoco quiero dejar de mencionarlo. No cabe ninguna duda sobre el papel que tuvieron en el alza del nivel medio cultural español. Tampoco cabe duda de que los profesores se elegían con esmero; tenían prestigio por sí mismos, como lo tenía el catedrático de universidad. Se exigía de ellos una buena enseñanza, pues de ella dependía el éxito futuro en la universidad. ¿Podriamos decir que nuestras universidades están en vías de convertirse en unos "Institutos de Enseñanza Superior" para
impartir un "SuperBUP"?

Habría que integrar la Formación Profesional en el sistema universitario. Gran parte de nuestra sociedad vive de oficios manuales, muchos de los cuales requieren conocimientos técnicos teóricos y prácticos que no se adquieren más que a través de buenos profesionales. Sobre su necesidad, huelgan comentarios. Sobre la conveniencia de que los profesionales lo sean de verdad, también. ¿Por qué no pueden ser estudios universitarios la orfebrenía, Ia artesanía, la fontanería y la electricidad, la carpintería y la marquetería y un largo etcétera? ¿Cree alguien que son técnicas simples? ¿Que no requieren responsabilidad?. Una de las tentaciones que hay que desechar es la de que todos los estudios hayan de tener esquemas análogos; si hay carreras de tres años, ¿por qué no de uno o dos? Tal integración eliminaría los ficticios complejos de superioridad ahora decantados a favor de los estudios universitarios (ficticios, sí, pues el éxito social con frecuencia se decanta en el otro lado) y que propicia la absurda avalancha que 
se registra hacia la universidad. Que cada cual pudiera elegir aquello para lo que realmente estuviera dotado, lo que realmente le gustara, que lo hiciera sin atender centenarios prejuicios sociales jsería tan maravilloso... y tan práctico...!

Nada se conseguiría, por supuesto, sin calidad en la enseñanza. Si el profesor no trabaja en su materia, poco y mal puede enseñar. Se debe ser exigente tanto en la selección del profesorado como en el mantenimiento de su actividad, y tan exigente como con el maestro se debe ser con la labor del alumno. $Y$ algo $m a ́ s$, algo más de la mayor importancia: la socicdad, que ya ha empapado totalmente a su Universidad, debe calcular cuánto quiere gastar en ella, de lo que resultará la calidad de la misma. ¿Formación de genios? Eso puede serinasequible. ¿Una función de guardería que atrase el momento del paro...? Eso puede costar relativamente poco (pero nunca nada). Pero entre aquello y esto hay muchas situaciones intermedias, siempre a ser satisfechas por el contribuyente. No puede hablarse de calidad, de exigencias, de formación ni de tantas otras cosas hasta que la sociedad española no se enfrente al problema del coste real de su Universidad, lo discuta y considerando to que quiere, decida.

No vale la pena insistir en todo ello, pero habría que pedir que cesara la infinita creación de "entes universitarios" en un sobrecogedor vacio de especialistas. Estos, se dice, los formará a medio y largo plazo la propia marcha de la universidad (escribo la palabra con minúscula), sí, pero en solitario, autarquísimamente, autodidactísimamente, al buen estilo español de la improvisación y de la individualidad... y a qué precio en lo económico y, sobre todo, en lo humano...!

Pero la labor más profunda habría que hacerla en el mismo concepto de Universidad. La comparacion de los estudios universitarios actuales con los del bachillerato en el siglo pasado no la he hecho a la ligera. Puede discutirse, criticar y condenar la proliferación de Facultades, Titulaciones y Universidades. Pero es un hecho, lamentable o no, con el que tendremos que convivir largo tiempo. No se puede pensar en una situación "a la inglesa" a corto o medio plazo, y de cualquier forma no se podría poner en práctica sin haber dado solución al paro universitario (irremediable, porque el número de puestos de rabajo que exigen un título universitario es finito) y a la enseñanza de oficios (que están clamando por una mayor categoría intelectual).

Así pues, aceptemos la situación actual como algo que, bien llevado, puede ser enomemente positivo: se ha acercado la Universidad clásica a la sociedad; 
en realidad, se ha fundido ya con ella. El nivel cultural, a poco bien que funcione el sistema, se elevara. Todos seremos universitarios. No habrá intelectuates de primera y de segunda. Pero ello no quita la necesidad de disponer de un buen sistepra de formación de dirigentes, sistema que habrá que crear como se creo, por la misma necesidad, la Universidad medieval, nuestra antecesora. Un buen sistema elitista, destinado a los mejores, pues a todos nos importa que nuestros dirigentes lo sean, vengan de la clase que vengan. No deben quedar a merced de la improvisación, del oportunismo, del azar, de la autodidáctica. ¿Habrá alguien que diga que la Universidad actual española ya posee tal sistema?.

Hemos cerrado así un ciclo milenario. ¿Cómo llamaremos al nuevo sistema disẹ̃ado para los más altos destinos?. ¿"Enseñanza de Cuano Ciclo" (pues nuestro doctorado, tal como es ahora, no cumple este papel)? "Universidad Superior"?...

¿Y quien creará estos estudios superiores? ¿La ONU? ¿Bruselas? ¡Por Dios que no! Sólo hay una salida: que sea la propia sociedad quien los organice. Si los pioneros americanos fueron capaces, ino va a ser capaz de hacerlo una Sociedad cuyos miembros sean todos universitarios? 